\title{
ARTICLE
}

\section{R\&D strategy on mid- and long-term behavior of fuel debris}

\author{
Kimihiko Yano ${ }^{\mathrm{a}^{*}}$, Toru Kitagaki ${ }^{\mathrm{a}}$, Tadahiro Washiya ${ }^{\mathrm{a}}$, Yasuaki Miyamoto ${ }^{\mathrm{b}}$ and Toru Ogawa ${ }^{\mathrm{b}}$ \\ a Japan Atomic Energy Agency (JAEA), 4-33 Muramatu, Tokai-mura, Naka-gun, Ibaraki-ken, 319-1194, Japan; 'bapan Atomic \\ Energy Agency (JAEA), 790-1 Motooka Ohtsuka, Tomioka Town, Futaba County, Fukushima 979-1151, Japan
}

\begin{abstract}
According to the mid- and long-term roadmap for decommissioning the Fukushima Daiichi Nuclear Power Station, fuel debris retrieval will start in 2021, after a decade of fuel debris generation. Some fuel debris will remain in the reactors until the end of defueling, but storage will be necessary for the fuel debris that is removed from the reactors. To develop a post-accident plan for the fuel debris, it is essential to consider the state and characteristics of this material over several decades. For these reasons, JAEA has created a preliminary R\&D strategy for the mid- and long-term behavior of fuel debris and is starting to develop fundamental studies on the issue mentioned earlier in cooperation with domestic universities and other research institutes.
\end{abstract}

Keywords: Fukushima Daiichi Nuclear Power Station; decommissioning; fuel debris; stability; aging

\section{Introduction}

At the Fukushima Daiichi Nuclear Power Station (FDNPS), a loss-of-coolant accident occurred during the Great East Japan Earthquake on March 11, 2011; this resulted in severe damage to the reactor cores of all the units from 1 to 3 . After this accident, the Nuclear Emergency Response Council was established mainly by the government and the Tokyo Electric Power Company-presently Tokyo Electric Power Company Holdings, Incorporated. Thus, a mid- and long-term roadmap for decommissioning the FDNPS [1] was created.

According to the roadmap, fuel debris retrieval will start in 2021, after a decade of fuel debris generation. It has been estimated that it will take three or four decades to complete this work, and it will be necessary to store the fuel debris that is removed from the reactors. To plan for post-accident operations such as defueling and storage, it is essential to consider the state and characteristics of the fuel debris over several decades, because we have limited knowledge on mid- and long-term stability of fuel debris and it is important to discuss on the possible issue of fuel debris retrieval due to fuel debris aging.

In this study, we discuss the R\&D strategy for the mid- and long-term behavior of the fuel debris as well as the approaches and roadmap for this R\&D project.

*Corresponding author. Email: yano.kimihiko@jaea.go.jp

\section{R\&D strategy}

\subsection{Targets}

Currently, as there very limited data on the aging process of fuel debris is available, it is difficult to discuss any problems that may be caused by fuel debris aging during the decommissioning of FDNPS. Therefore, our targets for this R\&D project are as follows:

- To clarify the mechanisms of fuel debris aging under assumed future conditions;

- To suggest a fundamental policy regarding aged-fuel debris over several decades after the conclusion of the defueling operation and FDNPS decommissioning;

- To predict possible problems caused by fuel debris aging.

\subsection{Approaches (implementation techniques)}

Based on these targets, we have considered the techniques necessary to implement this strategy, in discussions with domestic experts on the topics relevant to this study such as nuclear power plant accidents and thermodynamics of fuel materials.

Figure 1 shows a schematic of the procedure of this $\mathrm{R} \& \mathrm{D}$ project. We have identified the following four main themes.

\subsubsection{Characterization of the fuel debris aging process}

Fuel debris characterization requires consideration of the initial states of the target materials. As for a previous study, the characterization for FDNPS decommissioning operations has been implemented by JAEA — a member 
of the International Research Institute of Nuclear Decommissioning (IRID) [2]. The dominant types of fuel debris in the FDNPS are assumed to be $\mathrm{UO}_{2}$, $(\mathrm{U}, \mathrm{Zr}) \mathrm{O}_{2}, \quad \mathrm{Zr}(\mathrm{O}), \quad$ and $\mathrm{Fe}-\mathrm{Zr}$ alloy $[3,4]$. The characteristics of these materials were evaluated in the same study. However, data on $\mathrm{Pu}$ and minor actinides were very limited because these elements were considered not to be dominant in determining the physical and mechanical properties that are important for the defueling operation. Thus, we established the following implementation techniques that are studied in this theme:

- Review of knowledge and experience gained from past events, such as the TMI-2 accident [5], past research results on severe accidents, and $\mathrm{R} \& \mathrm{D}$ results for $1 \mathrm{~F}$ decommissioning.

- Discussion of the dominant types of fuel debris.

- Clarifying the chemical and physical state of important elements such as $\mathrm{Pu}$ and other actinides.

The outputs of this issue will be helpful for preparing starting materials of experimental approaches on aging mechanisms.

\subsubsection{Environmental conditions affecting the aging process}

It is also important to consider environmental conditions that can affect the fuel debris aging process over the mid- and long-term. These conditions will change during the progress of decommissioning the FDNPS. To consider these effects, we have to assume various decommissioning scenarios then estimate the conditions around the fuel debris that result from the operations under the assumed conditions. The implementation techniques for this theme were therefore, set as follows:

- Rough scenario study of the operations in $1 \mathrm{~F}$ decommissioning, from defueling to storage of the fuel debris.

- Estimation of the conditions affecting fuel debris aging, such as temperature, atmosphere, cation/anion concentration in the water, and radiolysis.

The outputs of this issue will be helpful for considering conditions of experimental approaches on aging mechanisms.

\subsubsection{Aging mechanisms}

On the basis of the information about the initial materials and experimental conditions mentioned in 2.2.1 and 2.2.2, we will use experimental and computational methods to study and clarify the mechanisms of fuel debris aging, which are essential to determine the future state of the fuel debris, and discuss methodologies concerned with the aging debris. We have categorized the relevant mechanisms into the following three types: chemical reactions, physical/mechanical fractures, and microbial degradation. It will be necessary to employ a variety of approaches to clarify these three mechanisms. In addition, we must consider the coupling between them, such as the relation of chemical stability and surface conditions to mechanical fracture. The following are the implementation techniques used in this theme:

- Clarifying the mechanisms of fuel debris aging using experimental and computational approaches.

- Considering the following three types of mechanisms:
a. Chemical reactions
b. Physical/mechanical fractures
c. Microbial degradations.

- Considering coupling between these three mechanisms.
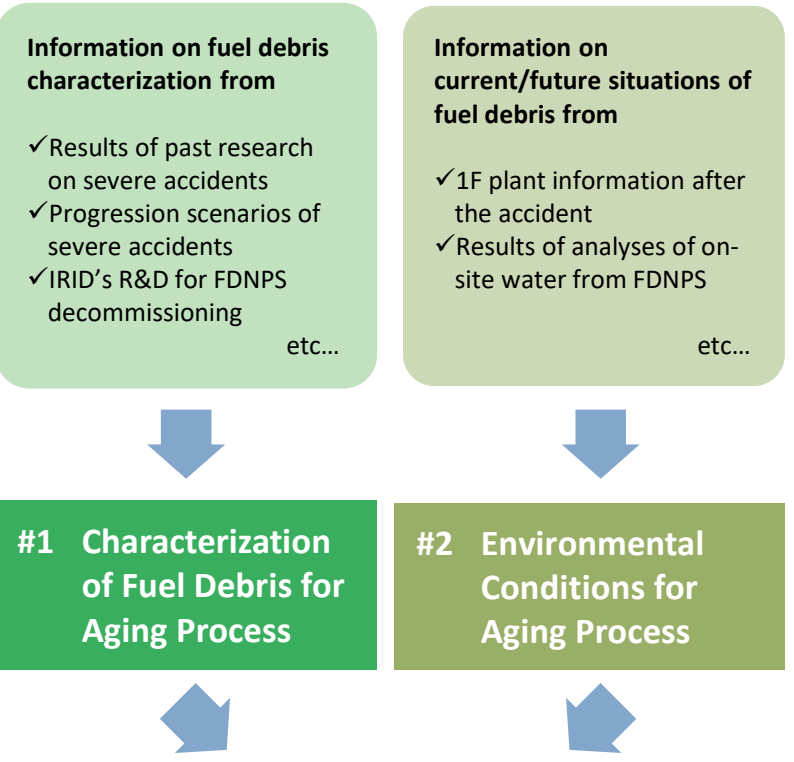

Summarization of fuel debris characterization and environmental conditions for aging process

\#3 Aging Mechanisms

\#4 Methodology for Future State Estimation

\section{Outputs}

- A fundamental policy on fuel debris aging for FDNPS defueling and storage

- Assumed problems by fuel debris aging in FDNPS decommissioning operations

Figure 1. Schematic of the procedure for $R \& D$ on the midand long-term behavior of fuel debris. 


\subsubsection{Methodology for future state estimates}

The final outputs of this study are a fundamental policy on fuel debris aging for FDNPS defueling and storage and for the identification of potential problems in fuel debris aging during FDNPS decommissioning operations. To create these outputs, we have to estimate the possible future states of the fuel debris from the results of the above themes. However, since clarification of all relevant mechanisms may take a considerable length of time, it is important to give preference to the identification of the dominant mechanisms that significantly affect the state of the fuel debris. This requires the following techniques:

- Discussion of the methodology for estimating fuel debris aging;

- Identification of the dominant aging mechanisms on the basis of the results of 2.2.1, 2.2.2, and 2.2.3;

- Development of methods and logistics for rough estimates of environmental conditions and the aging time for the dominant mechanisms;

- Development of a fundamental policy on fuel debris aging for countering the potential problems caused by it.

\subsection{Schedule}

The schedule for this $R \& D$ project is shown in Figure 2. In this plan, our preliminary study will start in the present Japanese fiscal year. We will summarize the results by the end of JFY2019, review the strategy of this project, and determine the need for its future continuation. In addition, as fuel debris retrieval will begin soon, we must achieve results in the next few years to affect the planning for the defueling operations.

This schedule is provisional at the present time, and it should be reviewed appropriately along with the strategy for this project.

\subsection{Implementation system}

It is difficult for any single organization to achieve essential results in such a short term of three years. Thus, it is necessary to cooperate with domestic/foreign universities and research institutes to support the long-term mission of decommissioning the FDNPS. Collaboration with domestic universities is particularly important from the viewpoint of human resource development for future FDNPS decommissioning work.

Also, this project should be implemented on the basis of the fundamental R\&D platform by CLADS/JAEA for decommissioning technology development. We will also collaborate with other decommissioning projects and R\&D programs.

\section{Conclusion}

JAEA has directed the R\&D strategy for mid- and long-term behavior of fuel debris on a preliminary basis and is now making a start on fundamental studies in cooperation with domestic universities and other research institutes.

\section{JFY 2017 \\ <Mid-and long-term roadmap for FDNPS decommissioning work>}

2019

$2020-$

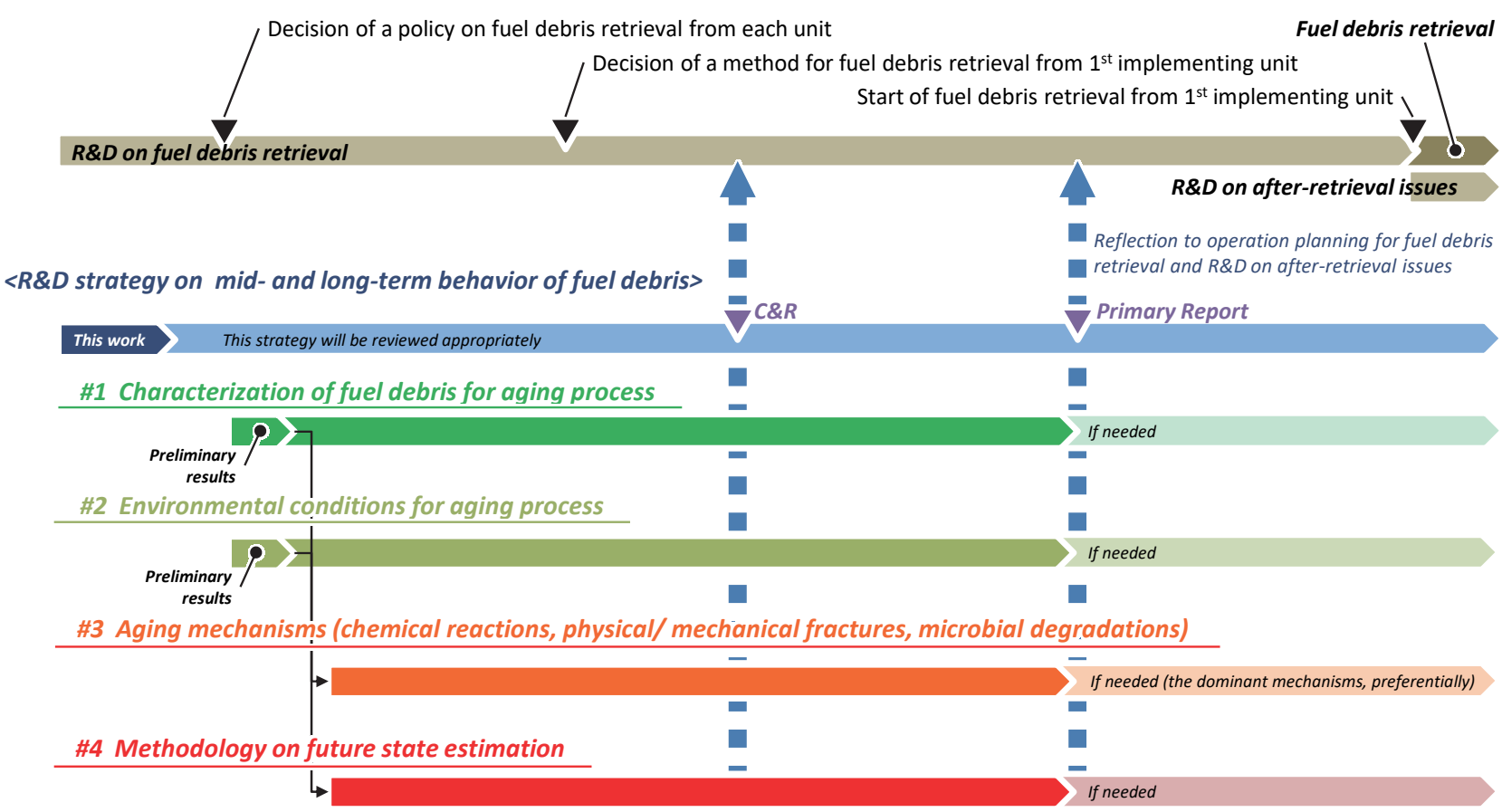

Figure 2. Provisional schedule of R\&D on mid- and long-term behavior of fuel debris. 
This strategy will be reviewed appropriately and concrete plans for each R\&D theme will be discussed with JAEA and the other collaborators mentioned earlier.

\section{Acknowledgements}

This work was supported by the Nuclear Damage Compensation and Decommissioning Facilitation Corporation (NDF). The authors would like to express their sincere appreciation to the members of the special interest group on the aging process of fuel debris for their valuable discussions and suggestions.

\section{References}

[1] Inter-Ministerial Council for Contaminated Water and Decommissioning Issues, Mid- and Long-Term Roadmap towards the Decommissioning of TEPCO's Fukushima Daiichi Nuclear Power Station, (2015).

http://www.meti.go.jp/english/earthquake/nuclear/d ecommissioning/pdf/20150725_01b.pdf

[2] T. Washiya, H. Ogino, M. Takano, K, Yano and N. Kaji, Approach to estimating fuel debris properties generated in Fukushima Daiichi NPS, The Proceedings of HOTLAB2016, (2016), S1.

[3] H. Ikeuchi, Y. Kondo, Y. Noguchi, K. Yano, N. Kaji and T. Washiya, Suggestion of typical phases on in-vessel fuel debris by thermodynamic calculation for decommissioning technology of Fukushima-daiichi nuclear power station, The Proceedings of GLOBAL 2013, (2013), p.8174.

[4] T. Kitagaki, K. Yano, H. Ogino and T. Washiya, Thermodynamic evaluation of the solidification phase of molten core-concrete under estimated Fukushima Daiichi nuclear power plant accident conditions, J. Nucl. Mater. 486 (2017), pp. 206-215.

[5] For example, Electric Power Research Institute, The cleanup of Three Mile Island Unit 2, a technical history: 1979 to 1990, EPRI NP-6931 (1990). 